\title{
Stress in Anesthesiologists: A Review
}

\author{
Shallu Chaudhary ${ }^{1}$, Neha Atwal ${ }^{2}$ \\ ${ }^{1}$ Medical Officer, Health \& Family Welfare Department, Himachal Pradesh, India \\ ${ }^{2}$ Junior Resident, Department of Anaesthesiology, IGMC Shimla, Himachal Pradesh, India
}

Corresponding Author: Neha Atwal

\begin{abstract}
Anaesthesia has emerged as one of the most stressful branches owing to the work it involves like emergency, critical care and other difficult patient situations. This occupational stress leads to the development of burnout syndrome among the anesthesiologists. This is characterized by emotional exhaustion, depersonalization and lack of personal accomplishments resulting in medical errors and deterioration of performance. A vast amount of literature is available listing the various causes of this syndrome. Appropriate stress managing strategies are advocated to reduce the stress sources.
\end{abstract}

Keywords: Stress, Anesthesiologists,

Anaesthesia

\section{INTRODUCTION}

There are several branches of medicine that are associated with a considerably high risk of psychological stress $^{1}$. Anaesthesia as a branch to practice is one of them. The work profile of anaesthetist includes areas such as delivering anaesthesia to patients in the operation theatre, emergency and critical care, management of acute and chronic pain. In the educational institutes there is an added responsibility of teaching, research and administration. Moreover in the recent times, the COVID- 19 pandemic has been a major contributing factor to the stress. The need of anesthesiologists has been greatly felt during these tough times and there has been an overburden of work, leading to stress.

A certain amount of stress when handled with a proper cognitive approach can have beneficial effects and improve one's ability to face challenges ${ }^{2}$. But an extreme level of stress will affect the physicians' physical and mental well being ${ }^{3}$ and can lead to a psychological syndrome called burnout ${ }^{4}$.

\section{BURN OUT SYNDROME}

Burnout syndrome is defined as emotional exhaustion, depersonalization and lack of personal accomplishments ${ }^{5}$ occurring in response to chronic occupational stress. It has a prevalence of about $50 \%$ in the medical population ${ }^{6}$. It occurs commonly in the anesthesiologists and is associated with adverse patient outcomes and increased medical errors affecting physician's professionalism ${ }^{7}$. Lack of appropriate support from the health care system is an important contributing factor. The presence of burnout leads to relationship impairment among the team members and this leads to decreased work quality. Further it also leads to the development of major depression and substance abuse among the physicians. Thus it is a serious matter concerning the performance and well being of the healthcare worker and affecting the patient care.

\section{REVIEW OF LITERATURE}

A study ${ }^{8}$ was conducted in which questionnaires were used to study the burnout syndrome and it showed low job satisfaction in $47.7 \%$ and depersonalization in $48.5 \%$. The prevalence was found to be $10.4 \%$ and occurred mainly among men 
(64.2\%). There was no difference between married and unmarried doctors.

Kain et $\mathrm{al}^{9}$ reported that many anesthesiologists have symptoms of chronic stress, sources of which include competence related factors, production pressures, long and odd working hours, including night calls, fear of litigation, financial uncertainty and interpersonal relationships.

Lindfors et $\mathrm{al}^{10}$ found that one in four anesthesiologists seriously thought of committing suicide some time or the other with higher incidence in people with poor health, low social support, and family problems. Various factors are found to be held responsible for professional burnout in anesthesiologists. Sleep deficit, night on call duties, irregular working hours due to the emergency cases leads to irregular sleep patterns.

Hawton et $\mathrm{al}^{11}$ in their study found that there was a higher rate of suicide in female doctors than males and that anesthesiologists along with psychiatrists, general practitioners had higher suicide rates than the other specialists. Anesthesiologists working in teaching hospitals have better working conditions, more OT room assistance and better academic environment resulting in better job satisfaction as compared to those working in community hospitals.

The Australian anesthetic incident monitoring study has shown that quality of anesthetic assistance is associated with both the development and resolution of critical incidents $^{12}$. From 5837 reports, adequate assistance contributed in 187 cases while skilled assistance in 808 cases minimized the incidents.

Jenkins and Wong $^{13}$ in their study found that the senior Canadian respondents got higher regards from surgeons in comparison to the younger ones. In a Californian study, 96\% anesthesiologists had great working relationships with surgeons, but slightly over half did not believe that surgeons understand the risk of anaesthesia. Surgeons pressurize to proceed with cases despite high risk and this hastens anesthetic procedures leading to stress.

De Oliveira $\mathrm{Jr}$ et $\mathrm{al}^{14}$ conducted a study on US residents and found an association between burnout and low quality of care delivered (more medication errors and/or a lower rate of best practice in anesthesiology). They also reported that high workload (70 hours/week) is associated with a higher incidence of burnout and depression.

Nyssen et al ${ }^{15}$ reported that the main sources of stress described by anesthesiologists were the lack of control overtime management, their busy work plan, the complexity of clinical tasks, and the huge sense of clinical responsibility.

Portuguese anesthesiologists found that the main factors generating stress were strained professional relationships, unskilled leadership by superiors, work overload, indiscipline of surgeons, lack of adequate work conditions and technically challenging situations ${ }^{16}$.

Brazilian anesthesiologists reported that working night shifts was the most frequent feature of anesthesiologists classified with burnout syndrome ${ }^{17}$. The work related predisposing conditions in anesthesiology may be due to the reduced interaction with patients and their families.

There has been a relationship between the work pattern and the time management in the occurrence of burnout syndrome. Downey et al found lower risk of burnout in anesthesiologists with academic practice as compared to those working in the private setting ${ }^{18}$ and Rui et al showed a higher risk of burnout in those working in urban and large scale hospitals.

\section{BEATING BURNOUT SYNDROME}

The first step is to accept the fact that stress is not a sign of weakness. Stress can affect any human being and we as doctors are no exception. We have to recognize the nature and cause of stress and develop strategies to cope with it. Personal and family time is very important. Appropriate stress management skills 
should be promoted like counseling in the training of all junior anesthesiologists to combat stress. Duty hours for both day and night shifts should be adequately defined. There should be vacations at regular intervals so that the anesthesiologist can destress. Workshops must be conducted at regular intervals educating about the strategies to beat stress.

\section{CONCLUSION}

There is a high prevalence of burnout syndrome in anesthesiologists. Mostly the factors involved are work overload, long erratic working hours, on call night duties, poor social life. Multiple studies have been conducted so far over the years and a significant amount of literature is available listing the possible causes of stress among anesthesiologists. However, the key is identifying the problem and accepting it. Stress coping strategies must be promoted and the health care officials must motivate each other and develop a friendly and healthy work environment.

\section{Acknowledgement: None}

\section{Conflict of Interest: None}

\section{Source of Funding: None}

\section{REFERENCES}

1. C.L. Cordes and T. W. Dougherty, "A Review and an Integration of Research on Job Burnout," The Academy of Management Review, vol. 18, no. 4, p.621, 1993.

2. S. H. Jackson, "The role of stress in anaesthetists' health and well being," Acta Anaesthesiologica Scandinavica, vol. 43, no. 6, pp. 583-602,1999.

3. L.N. Dyrbye, M.R. Thomas, F.S. Massie et al., "Burnout and suicidal ideation among U.S. medical students," Annals of Internal Medicine, vol. 149, no.5, pp.334-341,2008.

4. Grau, R. Suner, and M. M. Garcia, "Burnout syndrome in health workers and relationship with personal and environmental factors," Gaceta Sanitaria, vol. 19, pp. 463-470,2005.

5. Maslach, S. E. Jackson, and M. P. Leiter, "Maslach burnout inventory," in Evaluating
Stress: A Book of Resources, vol. 3, pp. 191-218, 1997.

6. T.D. Shanafelt, O. Hasan, L.N. Dyrbye et al., "Changes in Burnout and Satisfaction with Work-Life Balance in Physicians and the General US Working Population between 2011 and 2014," Mayo Clinic Proceedings, vol. 90, no. 12, pp. 1600$1613,2015$.

7. L.N. Dyrbye, F.S. Massie Jr., A. Eacker et al., "Relationship between burnout and professional conduct and attitudes among US medical students," The Journal of the American Medical Association, vol. 304, no. 11, pp. 1173-1180,2010.

8. Svensen E, Arnetz BB, Ursin H, Eriksen HR. Health complaints and satisfied with the job? A cross-sectional study on work environment, job satisfaction, and subjective health complaints. J Occup Environ Med 2007;49:568-73.

9. Kain ZN, Chan KM, Katz JD, Nigam A, Fleisher L, Dolev J, et al. Anesthesiologists and acute perioperative stress: A cohort study. Anesth Analg 2002;95:177-83.

10. Lindfors PM, Meretoja OA, Luukkonen RA, Elovainio MJ, Leino TJ. Suicidality among Finnish anesthesiologists. Acta Anaesthesiol Scand 2009;53:1027-35.

11. Hawton K, Clements A, Sakarovitch C, Simkin S, Deeks JJ. Suicide in doctors: A study of risk according to gender, seniority and specialty in medical practitioners in England and Wales, 1979-1995. J Epidemiol Community Health 2001;55:296300.

12. Kluger MT, Bukofzer M, Bullock M. Anaesthetic assistants: Their role in the development and resolution of anaesthetic incidents. Anaesth Intensive Care 1999;27: 269-74.

13. Jenkins K, Wong D. A survey of professional satisfaction among Canadian anesthesiologists. Can J Anaesth 2001; 48:637-45

14. G.S. De Oliveira Jr., R. Chang, P.C. Fitzgerald et al., "The prevalence of burnout and depression and their association with adherence to safety and practice standards: a survey of United States anesthesiology trainees," Anesthesis \& Analgesia, vol. 117, no. 1, pp. 182-193, 2013.

15. A.S. Nyssen, I. Hansez, P. Baele, M. Lamy, and V. de Keyser, "Occupational stress and burnout in anaesthesia," British Journal of 
Anaesthesia, vol. 90, no. 3, pp. 333-337, 2003.

16. Morais, P. Maia, A. Azevedo, C. Amaral, and J. Tavares, "Stress and burnout among Portuguese anesthesiologists," European Journal of Anesthesiology, vol.23,no.5, pp.433-439,2006.

17. E. Magalhaes, A. C. de Sousa Oliveira, C.S. Goveia, L.C. Ladeira, D.M. Queiroz, and C.V.Vieira, "Prevalence of burnout syndrome among anesthesiologists in the Federal District ," Brazilian Journal of Anesthesiology (English Edition), vol.65, no.2,pp.104-110,2015.
18. R.L.Downey, T. Farhat, and R. Schumann, "Burnout and coping amongst anesthesiologists in a US metropolitan area: A pilot study," Middle East Journal of Anesthesiology, vol.21,no.4, pp.529-534, 2012.

How to cite this article: Chaudhary S, Atwal N. Stress in anesthesiologists: a review. International Journal of Science \& Healthcare Research. 2021; 6(3): 281-284. DOI: https:// doi.org/10.52403/ijshr.20210749 